\title{
CYTOTOXIC ACTIVITY OF Ciona intestinalis (Tunicata) HEMOCYTES: PROPERTIES OF THE IN VITRO REACTION AGAINST ERYTHROCYTE TARGETS
}

\author{
Nicolo' Parrinello, Vincenzo Arizza, Matteo Cammarata, and \\ Daniela M. Parrinello \\ Institute of Zoology, University of Palermo, Via Archirafi, 18, 90123 Palermo, Italy \\ (Submitted Oclober 1991; Accepted March 1992)
}

\begin{abstract}
$\square$ Abstract-Hemocytes (effectors) of Ciona intestinalis showed a natural cytotoxic capacity (HCA) when assayed in vitro against erythrocytes (targets). Cytotoxic cells lysed, to a variable extent, rabbit (RE), human (A, B, O), guinea pig, and sheep (SE) erythrocytes. Hemocyte cytotoxic activity (HCA) assayed against $\mathrm{SE}$ is a calcium-dependent reaction, occurs rapidly $(15-30 \mathrm{~min})$, at $25-37^{\circ} \mathrm{C}$ over a wide range of $\mathrm{pH}(5.4-8.0)$. Assays were carried out using: 1) the medium in which hemocytes were maintained, 2) the soluble portion of hemocyte lysates, and 3) debris prepared from hemocyte lysates. Results suggest that HCA is a cell-mediated process that requires effectortarget cell contacts. Anti-SE (calciumdependent) and anti-RE (calcium-independent) agglutinins were also found in the reaction medium, probably released by hemocytes as a consequence of the in vitro experiments. The occurrence of HCA was independent of any allogeneic reaction between mixed hemocytes. Various levels of cytotoxic activity reveal hemocyte specificity.
\end{abstract}

$\square$ Keywords-Hemocytes; Hemolysins; Invertebrates; Tunicate; Ciona intestinalis; Cytotoxicity; Sheep erythrocytes.

\section{Introduction}

Natural killing activity as a defense function, independent of phagocytosis, probably appeared early during the evolution of the immune system (1). In mammals, cell killing by immune or nonimmune

Address correspondence to Professor Nicolo' Parrinello. cells represents a defense against foreign targets, including transformed cells, virus-infected cells, parasites, and other pathogenic invaders [see $(2,3)$ for reviews]. The cell-killing mechanism can involve soluble cytotoxic mediators or it requires contact between effector and target cells [reviewed in $(2,3)$ ]. Natural killer (NK) cells are non-MHC-restricted lymphocytes that show lytic activity, independent of antigenic induction, against a variety of target cells $(1,2)$. They are thought to be the evolutionary precursors of cytotoxic T cells (4). Similar cellular mechanisms exist in the invertebrates (1). Natural cytotoxic activity directed against xenogeneic or malignant cells has been demonstrated in sipunculids $(5,6)$, annelids (7), molluscs $(7,8)$ echinoderms $(7,9,10)$, and arthropods $(11-13)$.

In tunicates, Fuke (14) observed that a contact reaction leading to mutual lysis can occur in vitro between xenogeneic and allogeneic hemocytes of several ascidian species. Cytotoxic activity by hemocytes was also observed in Styela (15) and in nonfusion reactions between allogeneic Botryllus colonies (16). With respect to Ciona intestinalis, hemocytes are capable of xenogeneic contact reactions (14). Moreover, granulocytes react against erythrocytes injected into the tunic and are probably responsible for tissue lysis (17-19). The mechanisms responsible for cell-killing reactions are still poorly understood. 
Lymphocyte-like cells, implicated in the reaction of tunic allografts in Styela plycata, may be responsible for antigraft responses; their influx is coincident with the decline in other cell types. According to one view, the rejections of experimentally transplanted living tissue are due to the cytotoxic effect of lymphocyte-like cells and their capacity to divide $(20,21)$. As a model for testing cytotoxicity, erythrocytes represent useful cell targets for assaying lytic activity of hemocyte effector cells. Here we examine in vitro cytotoxic activity of hemocytes from Ciona intestinalis against sheep erythrocyte targets.

\section{Materials and Methods}

\section{Tunicates}

Living Ciona intestinalis were collected from Porticello harbor (Gulf of Palermo).

\section{Bleeding, Hemocyte Preparation, and Quantification and Dialysis of Plasma}

Hemolymph was withdrawn from the heart with a syringe containing artificial sea water without $\mathrm{CaCl}_{2}$ and $\mathrm{MgCl}_{2}$ but enriched with $100 \mathrm{~m} M$ EDTA (FSWEDTA) as an anticoagulant ( $/ \mathrm{v})$. The hemolymph from about 200-300 specimens was pooled. Hemocytes were separated from plasma by centrifugation at $1500 \times$ $g$ for $15 \mathrm{~min}$ at $4^{\circ} \mathrm{C}$, washed three times in Tris-buffered saline ( $10 \mathrm{~m} M$ Tris- $\mathrm{HCl}, \mathrm{pH}$ $8,150 \mathrm{mM} \mathrm{NaCl}$ ) (TBS), and finally suspended in TBS containing $10 \mathrm{mMC} \mathrm{CaCl}$ (TBS-Ca) to obtain a $1-1.5 \times 10^{7} / \mathrm{mL}$ cell concentration (unless otherwise indicated). Total cell counts were determined using an improved Neubauer hemocytometer. Hemocyte mortality was evaluated by the trypan blue $(0.2 \%$ in TBS) exclusion test: mortality values ranging from 1.0 to $5.0 \%$ were found in all experiments after periods of $30-60$ min. The plasma was dialyzed against phosphate-buffered saline, $\mathrm{pH} 7.4$ (PBS), before assaying it to test for hemagglutinating activity against sheep (SE) and rabbit (RE) erythrocytes.

\section{Preparation of Erythrocyte Targets}

Human A, B, and $\mathrm{O}$ erythrocytes were supplied from the Avis Transfusion Center, University General Hospital (Palermo). Sheep and guinea pig erythrocytes (GPE) were provided by the Zooprophylaxis Institute (Palermo), whereas RE were a commercial preparation (Sclavo, Siena). Erythrocytes were washed three times in PBS, then in TBS$\mathrm{Ca}^{2+}$, and finally suspended in that medium at the required concentration. To obtain comparable results, SE used in the cytotoxic assays were derived from the same donor.

\section{Experimental Cytotoxic Assay}

A $200-\mu \mathrm{L}$ sample of hemocyte suspension $\left(2-3 \times 10^{6}\right.$ cells $)$ in TBS-Ca ${ }^{2+}$ was mixed with an equal volume of freshly prepared SE suspension $\left(8 \times 10^{6}\right.$ cells) in TBS- $\mathrm{Ca}^{2+}$. The mixture was incubated with continuous and moderate shaking at $37^{\circ} \mathrm{C}$ for $1 \mathrm{~h}$, and hemoglobin (Hb) release was determined at $541 \mathrm{~nm}$ after removing intact cells by centrifuging the reaction mixture at $1500 \times g$ for $15 \min$ at $4^{\circ} \mathrm{C}$.

The percent of hemolysis was calculated according to the following formula:

$$
\begin{aligned}
& \% \mathrm{Hb} \text { released }= \\
& \frac{\text { test release }- \text { spontaneous release }}{\text { maximum release }- \text { spontaneous release }} \\
& \times 100 .
\end{aligned}
$$

Maximum hemoglobin release was obtained by preparing an erythrocyte sus- 
pension in distilled water at room temperature. Control erythrocyte suspensions were prepared in the same medium of the reaction mixture and incubated under the same experimental conditions (spontaneous release). To evaluate the effect of an acidic $\mathrm{pH}$, TBS- $\mathrm{Ca}^{2+}$ at $\mathrm{pH}$ 5.4 was used as the reaction medium.

\section{Cytotoxic Assay of Hemocyte Preparations From Individual Ciona}

Hemocyte cytotoxic activity (HCA) from each of 70 Ciona was evaluated. The cells from each hemolymph sample $(0.3-1.0 \mathrm{~mL})$ were pelleted, washed, and suspended in $200 \mu \mathrm{L}$ TBS-Ca ${ }^{2+}$ to perform the assays.

\section{Statistical Analysis}

Hemocyte counts were determined in the final suspension. For each experiment three samples were prepared, the values representing the means $\pm \mathrm{SD}$. Statistical significance of differences between mean values was determined by Duncan's test (22).

\section{Hemagglutination Assay}

Hemagglutinating activity was determined with $1 \%$ suspersions of washed erythrocytes from sheep, rabbit, and human in microtiter plates (Cooke Engineering Co. Alexandria, VA) following a standard method (23) and using TBS or TBS- $\mathrm{Ca}^{2+}$ medium containing $0.1 \%$ gelatin. Titers were expressed as the reciprocal of the last dilution giving clear agglutination.

\section{Preparation of Cellular Debris and Lysate From Hemocytes, and Ghosts From Erythrocytes}

The cellular debris and lysate of Ciona hemocytes were obtained by son- ication (Vibra-Cell, Sonics \& Materials Inc., Danbury, CT) of $10 \mathrm{~mL}$ hemocyte suspension $\left(3 \times 10^{7} / \mathrm{mL}\right)$. Cellular debris was separated from the soluble portion by centrifugation at $27,000 \times g$ for 30 min, then washed four times in TBS or TBS-Ca ${ }^{2+}$. Sheep erythrocyte ghosts were prepared by washing them several times as a $5 \%$ suspension in distilled water or in hypotonic solution. In order to separate ghosts, the preparation was then centrifuged at $10,000 \times g$ for $30 \mathrm{~min}$ at $4^{\circ} \mathrm{C}$.

\section{Results}

\section{Condition Supporting \\ Hemocyte Viability}

Trypan blue exclusion test showed that $\mathrm{TBS}-\mathrm{Ca}^{2+}$ is a suitable medium for Ciona hemocyte suspensions. The hemocyte mortality after $24 \mathrm{~h}$ at $4^{\circ} \mathrm{C}$ or 1 $h$ at $37^{\circ} \mathrm{C}$ in $\mathrm{TBS}-\mathrm{Ca}^{2+}$ ranged from 1.0 to $5.0 \%$ (data not shown). Table 1 shows that, in a typical experiment, in the absence of $\mathrm{Ca}^{2+}$ ions, hemocytes did not lyse SE after 1 -h incubation at $37^{\circ} \mathrm{C}$, whereas $10 \mathrm{mMCaCl}$ appears to be the lowest salt concentration capable of producing hemolysis higher than 50\%; 100

\section{Table 1. Effect of Various Concentrations of Divalent Cation on the Cytotoxic Activity of Ciona intestinalis Hemocytes $\left(1-1.5 \times 10^{7} / \mathrm{mL}\right)$ Against Sheep Erythrocytes $\left(4 \times 10^{7} / \mathrm{mL}\right)$.}

\begin{tabular}{cc}
\hline $\begin{array}{c}\text { Reaction } \\
\text { Medium }\end{array}$ & $\begin{array}{c}\text { Hemolysis Degree } \\
(\% \pm \mathrm{SD})\end{array}$ \\
\hline TBS & $3.7 \pm 1.4$ \\
TBS $\mathrm{Ca}^{2+} 100 \mathrm{mM}$ & $82.6 \pm 10.2$ \\
TBS $\mathrm{Ca}^{2+} 10 \mathrm{mM}$ & $73.7 \pm 8.3$ \\
TBS $\mathrm{Ca}^{2+} 1 \mathrm{mM}$ & $9.0 \pm 3.4$ \\
TBS $\mathrm{Mg}^{2+} 100 \mathrm{mM}$ & $15.0 \pm 2.5$ \\
TBS $\mathrm{Mg}^{2+} 10 \mathrm{mM}$ & $2.6 \pm 0.7$ \\
TBS $\mathrm{Mg}^{2+} 1 \mathrm{mM}$ & $0.6 \pm 0.1$ \\
TBS $\mathrm{Ca}^{2+}-\mathrm{Mg} \mathrm{g}^{2+}$ & \\
$10+10 \mathrm{mM}$ & $26.5 \pm 6.7$ \\
TBS $\mathrm{Ca}^{2+} 10 \mathrm{mM}$ & $2.6 \pm 0.7$ \\
$+\mathrm{EDTA}^{2+} \mathrm{mM}$ & \\
\hline
\end{tabular}


$\mathrm{m} M \mathrm{CaCl}_{2}$ did not increase significantly the hemolytic reaction $(82.6 \%)$. In other experiments, reaction mixtures containing $10 \mathrm{mM} \mathrm{CaCl}$ reached hemolysis to a degree higher than $90.0 \%$. These results prompted the use of TBS enriched with $10 \mathrm{mMCaCl} \mathrm{CaBS}_{2}\left(\mathrm{Ca}^{2+}\right)$ as a standard medium. $\mathrm{MgCl}_{2}$ had a negligible effect on the HCA. Moreover, when $\mathrm{MgCl}_{2}$ was mixed with $\mathrm{CaCl}_{2}$ at the same concentration, a reduced hemolytic activity by hemocytes was observed (Table 1). Finally, $10 \mathrm{~m} M$ EDTA inhibited the hemolysis of erythrocytes in TBS- $\mathrm{Ca}^{2+}$.

Some Properties of Hemocyte Cytotoxic Activity (HCA) Against Sheep Erythrocytes

Figure 1 shows the hemolytic values plotted as effector cell (EC):target cell (TC) ratios. Hemolysis increased with the number of hemocytes in the reaction mixture; however, a plateau characterizes the diagram for a hemocyte number higher than $1.5 \times 10^{7} / \mathrm{mL}$ (EC:TC ratio about 1:3). To plot a kinetic curve, the reaction was interrupted in two experi-

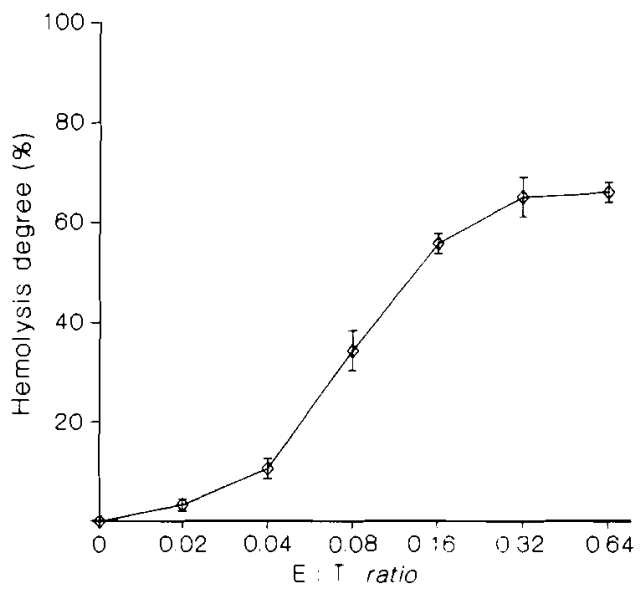

Flgure 1. Hemolytic values plotted against hemocytes (EC): sheep erythrocytes (TC) ratio. Dilutions of the Ciona intestinalis hemocyte suspension were assayed with constant erythrocyte numbers. ments at 15-min intervals: the slope of the curve increases from the first hemocyte-target contact (14\%), reaching the highest values $(85-92 \%)$ at $30-60 \mathrm{~min}$ (Fig. 2). Large clumps of mixed hemocytes-erythrocytes were observed microscopically shortly after performing the reaction mixtures. Plasma dialyzed against TBS, containing 10 or 100 $\mathrm{m} M \mathrm{CaCl}_{2}$, never caused lysis of erythrocytes.

\section{Effects of Temperature on Cytotoxicity}

The effect of increasing the incubation temperatures reveals no significant erythrocyte lysis at $0^{\circ} \mathrm{C}$, a sharp inflection at $25^{\circ} \mathrm{C}$, achieving the maximum at $30-37^{\circ} \mathrm{C}$ (Fig. 3). Hemocytes held for 24 $\mathrm{h}$ at $0-4^{\circ} \mathrm{C}$ maintained their cytotoxic activity $(80.0 \pm 5.1 \%)$ after washing and transferring them to the reaction mixture at $37^{\circ} \mathrm{C}$. No significant differences were found using the reaction medium at $\mathrm{pH}$ 8.0 or 5.4 , in two distinct experiments: 69.2-70.5\% and 69.0-72.1\% (SD from \pm 0.1 to \pm 4.4$)$ were the hemolytic values obtained.

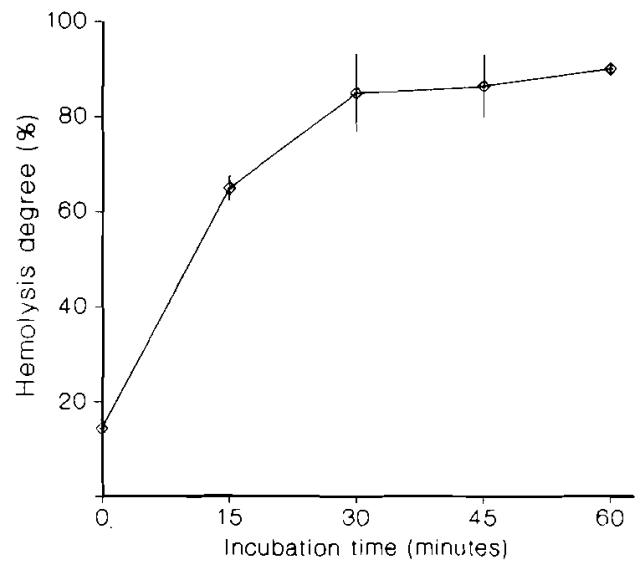

Figure 2. Time course curve of Ciona intestinalis hemocyte $\left(1-1.5 \times 10^{7} / \mathrm{mL}\right)$ cytotoxic activity against sheep erythrocytes $\left(4 \times 10^{7} / \mathrm{mL}\right)$. 


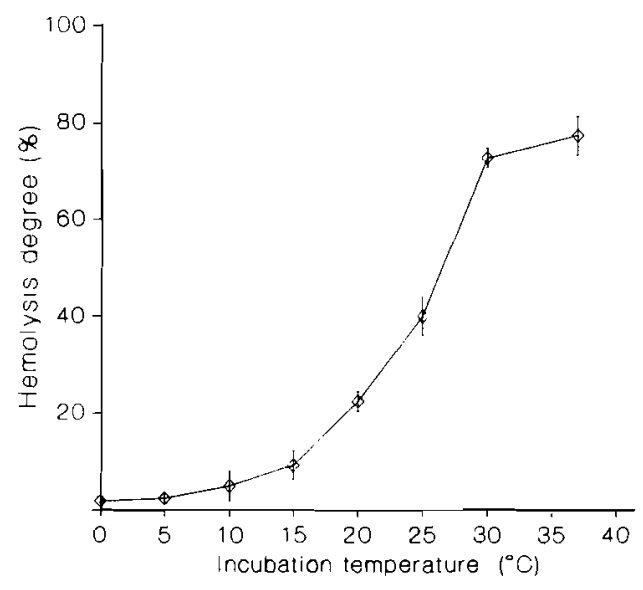

Figure 3. Effect of incubation temperature on Ciona intestinalis hemocyte $\left(1-1.5 \times 10^{7} / \mathrm{mL}\right)$ cytotoxic activity against sheep erythrocytes (4 $\times 10^{7} / \mathrm{mL}$ ).

\section{Erythrocyte Specificity, and}

Hemocyte Cytotoxic Activity of Individual Ciona Specimens

Hemocytes lysed sheep as well as rabbit, guinea pig, human A, B, and $\mathrm{O}$ erythrocytes (Table 2). Individual hemolytic activity varied depending on the Ciona donor. This variability appears to be related primarily to hemocyte numbers. Although HCA of samples from various specimens is statistically significant (linear regression, $p<0.002$ ) with increasing numbers of hemocytes, an evident difference was observed in cytotoxic activity by samples containing almost the same hemocyte number (Fig.

Table 2. Hemocyte Cytotoxic Activity of Clona Intestinalls (1-1.5 $\left.\times 10^{7} / \mathrm{mL}\right)$ Against Varlous Erythrocyte Types $\left(4 \times 10^{7} / \mathrm{mL}\right)$.

\begin{tabular}{cc} 
Erythrocyte Type & $\begin{array}{c}\text { Hemolysis Degree } \\
(\% \pm S D)\end{array}$ \\
\hline A & $64.6 \pm 5.6$ \\
B & $51.0 \pm 10.1$ \\
O & $36.6 \pm 6.4$ \\
AB & $53.0 \pm 8.0$ \\
RE & $51.6 \pm 7.4$ \\
GPE & $80.0 \pm 2.6$ \\
\hline
\end{tabular}

4). Similarly, hemolytic values obtained under standard conditions were compared between these various experiments. A constant number of 1.0-3.0 $\times$ $10^{7}$ cells $/ \mathrm{mL}$ caused HCA that ranged from 58.2 to $96.7 \%$ (Table 3 ).

\section{Properties of Cytotoxic Factor(s)}

To examine if active factor(s) is(are) released in the reaction medium as a consequence of experimental conditions, five different experiments were performed using $1.0-1.5 \times 10^{7} / \mathrm{mL}$ hemocytes preincubated in TBS-Ca ${ }^{2+}$ for $1 \mathrm{~h}$ at $37^{\circ} \mathrm{C}$. The supernatants obtained by centrifuging the suspensions at $1500 \times g$ for $15 \mathrm{~min}$ at $4^{\circ} \mathrm{C}$ were assayed for hemolytic activity against SE. The hemolytic response by hemocytes revealed control levels (55.1-90.8\%), whereas the values obtained using supernatants ranged from 0.1 to $11.0 \%$ (Table 3).

Since $\mathrm{Ca}^{2+}$ could have inactivated cytotoxic factors that could be released in the medium, two additional experiments were performed in which hemocytes were preincubated in the absence of $\mathrm{CaCl}_{2}$ and then incubated with an SE

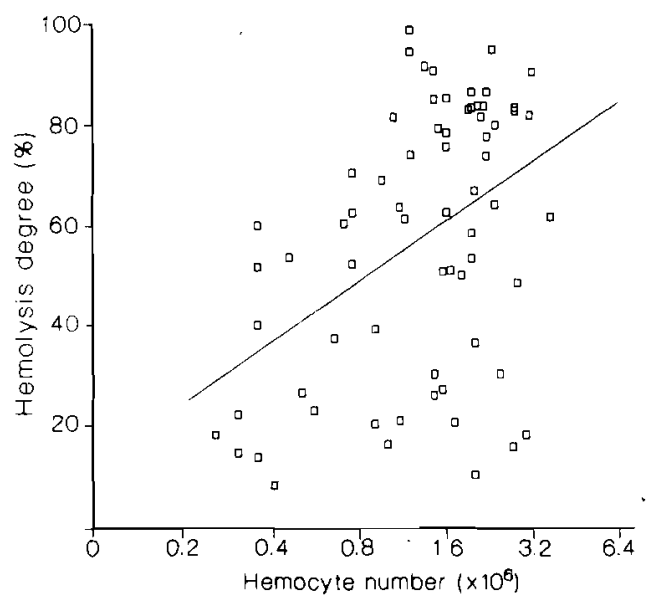

Figure 4. Hemocyte cytotoxic activity plotted against individual hemocyte numbers from 70 Ciona intestinalis specimens (regression equation: $y=-185.17+39.7 x$; correlation coefficient $r=0.473$ ). 
Table 3. Hemocyte Cytotoxlc Actlvity (HCA) of the Culture Medium Removed From Clona Intestinalis Hemocytes $\left(1-1.5 \times 10^{7} / \mathrm{mL}\right)$ Separated After $1-\mathrm{h}$ Prelncubation in the Presence or Absence of $\mathrm{Ca}^{2+}$ at $37^{\circ} \mathrm{C}$.

\begin{tabular}{|c|c|c|c|c|c|}
\hline \multirow{3}{*}{$\begin{array}{l}\text { No. } \\
\text { Exp. }\end{array}$} & \multirow{3}{*}{$\begin{array}{c}\text { HCA of the } \\
\text { Untreated } \\
\text { Samples }\end{array}$} & \multicolumn{4}{|c|}{$\begin{array}{l}\text { Hemolysis Degree }(\% \pm S D) \text { at Various } \mathrm{Ca}^{2+} \\
\text { Concentrations in the Preincubation Medium }\end{array}$} \\
\hline & & \multicolumn{2}{|c|}{$\mathrm{Ca}^{2+} 10 \mathrm{mM}$} & \multicolumn{2}{|c|}{$\mathrm{Ca}^{2+} 0.0 \mathrm{mM}$} \\
\hline & & Hemocytes & Supernatant & Hemocytes & Supernatant \\
\hline $\begin{array}{l}1 \\
2 \\
3 \\
4 \\
5\end{array}$ & $\begin{array}{l}59.5 \pm 4.7 \\
96.7 \pm 3.5 \\
62.8 \pm 6.2 \\
69.0 \pm 1.5 \\
58.2 \pm 0.1\end{array}$ & $\begin{array}{l}55.1 \pm 7.1 \\
90.8 \pm 0.5 \\
62.9 \pm 3.9 \\
68.0 \pm 0.2 \\
56.9 \pm 2.3\end{array}$ & $\begin{array}{r}4.4 \pm 1.4 \\
2.0 \pm 1.2 \\
11.0 \pm 5.0 \\
6.6 \pm 3.3 \\
0.1 \pm 0.0\end{array}$ & $\begin{array}{c}44.1 \pm 2.6 \\
98.1 \pm 6.1 \\
- \\
- \\
-\end{array}$ & $\begin{array}{c}3.2 \pm 1.2 \\
8.7 \pm 2.0 \\
- \\
-\end{array}$ \\
\hline
\end{tabular}

To evaluate the HCA against sheep erythrocytes $\left(4 \times 10^{7} / \mathrm{mL}\right), \mathrm{Ca}^{2+}$ concentration $(10 \mathrm{mM})$ was restored in the reaction mixture.

suspension in which $10 \mathrm{mM} \mathrm{CaCl}$ concentration was restored. No significant differences (Duncan's test; $\alpha=0.05$ ) in the hemolytic degrees of supernatants were observed compared to those of the standard medium (Table 3 ). The supernatants remained inactive $(1.6 \pm 1.0)$ even if hemocytes were preincubated for $1 \mathrm{~h}$ in the presence of ghosts from $6 \times 10^{7}$ $\mathrm{SE} / \mathrm{mL}$. Cell mortality before and after preincubations of hemocytes ranged from 3.0 to $4.5 \%$.

To ascertain if the active factor(s) are associated with cell membranes, hemocyte debris was assayed for cytotoxic activity. The washed debris, suspended in TBS-Ca ${ }^{2+}$, effected lysis of SE, producing 52.0-89.5\% ( $\mathrm{SD}= \pm 1.1$ ) hemolysis. On the contrary, hemocyte lysates obtained either in the presence or absence of $\mathrm{CaCl}_{2}$ were inactive. In fact, only in one out of four experiments did hemolysis reach $15.6 \pm 1.0 \%$, whereas in others the values ranged from 0.1 to $2.2 \%$.

\section{Hemagglutinating Activity of Supernatant From Hemocyte Suspensions and Hemolymph}

The supernatant obtained immediately after centrifuging hemocyte sus- pensions $\left(3 \times 10^{7} / \mathrm{mL}\right)$ agglutinated $\mathrm{SE}$ and RE $\left(4 \times 10^{7} / \mathrm{mL}\right)$. Hemagglutinating titers of $2-8$ and $2-4$, respectively, were found. The activity of supernatants did not increase after 1-2-h incubation of cells at $37^{\circ} \mathrm{C}$. The agglutinin released into the culture medium was examined using TBS enriched with 1,10 , and $100 \mathrm{mM}$ $\mathrm{CaCl}_{2}$. Results revealed that the anti-RE agglutinating activity did not change significantly under any of these conditions (titers 2-8). Moreover, $10 \mathrm{~m} M$ EDTA added to the medium (TBS) did not affect the agglutinating titer. On the contrary, anti-SE hemagglutinating activity of the supernatant was not evident when assayed in TBS without added $\mathrm{Ca}^{2+}$ and it was abolished in the presence of 10 m $M$ EDTA.

The negligible hemocyte death $(1.4 \%$ mortality) is probably not responsible for the release of agglutinins. In addition, hemocytes separated from the incubation medium retained their cytotoxic activity. Hemolytic values ranging from 73.3 to $75.8 \%$ (SD $=$ from \pm 3.5 to \pm 4.7 ) in the presence of $\mathrm{Ca}^{2+}$, and from 0.6 to $2.6 \%$ ( $\mathrm{SD}=$ from \pm 0.6 to \pm 1.2 ) in the absence of $\mathrm{Ca}^{2+}$, were obtained in three distinct experiments. Hemolymph also showed anti-SE calcium-dependent and 
calcium-independent anti-RE hemagglutinating activity at titers of $2-4$.

\section{Discussion}

Hemocytes possess a natural, calcium-dependent cell-killing system that was examined using erythrocytes as targets. Cytotoxic cells show a broad specificity and lyse, to a variable extent, rabbit, human ( $A, B, O)$, guinea pig, and sheep erythrocytes. Although the medium (TBS) we employed might not be ideal for long-term cultivation of invertebrate hemocytes, it is suitable for vertebrate erythrocytes in our short-term cytotoxic assay system. We chose it to minimize target damage by the medium so that cytotoxic potential of Ciona effector cells could be more accurately measured. In fact, using appropriate controls we found that the mortality of hemocytes held in that medium was at a very low level (1.0-5.0\%).

The activity of cytotoxic hemocytes can be totally arrested by lowering the temperature $\left(0-4^{\circ} \mathrm{C}\right)$. This may reflect a general metabolic effect of temperature or changes in the viscosity of the membrane matrix of target cells initiated by effector cells and propagated by temperature. It cannot be excluded that the target cell membrane could be irreversibly damaged at a first temperature-independent stage in the course of the effector-target once interaction is reached.

Hemocyte cytotoxic activity is apparently a cell-mediated reaction that requires that a contact is established between the effector-target cell membranes. Experiments performed to test if hemolysis depends upon release into the medium of a cytotoxic factor showed that soluble lytic factor(s) were not significantly present in the supernatant from hemocyte suspensions held under the same conditions as the reaction mixtures. There was only, occasionally, a degree of hemolysis higher than $10 \%$. Lytic factors were also not observed in the supernatant after stimulating hemocytes with erythrocyte ghosts. The lytic factors act over a wide range of $\mathrm{pH}$ (5.48.0 ), at brief time intervals $(15-30 \mathrm{~min})$, at $25-37^{\circ} \mathrm{C}$, and require $\mathrm{Ca}^{2+}$ cations for their activity. Calcium cannot be replaced by magnesium cations; $\mathbf{M g}^{2+}$ appears to compete with $\mathrm{Ca}^{2+}$, thus reducing hemolytic reactions when both cations are present in the medium. It is unclear if lytic factor(s) are secreted following contacts between hemocytes and viable erythrocytes.

Other results support the existence of a cytotoxic mechanism controlled by contacts between cell membranes. In fact, the lysate obtained by sonication of hemocytes in the reaction medium appeared to be inactive, whereas the cellular debris from sonicated hemocytes caused cytotoxicity. The presence of $\mathrm{Ca}^{2+}$ is probably not responsible for inactivation of soluble lytic factors, since low hemolytic values were observed even when hemocyte lysates were obtained in TBS deprived of $\mathrm{Ca}^{2+}$, and supernatants from $\mathrm{Ca}^{2+}$-free reaction mixtures were assayed. With respect to hemolytic activity provoked by hemocyte debris, a role of the plasma membrane is not clear. In fact, preparations of debris are composed of particles from various cell membranes and organelles after sonication.

To avoid possible interactions between allogeneic hemocytes that could activate cytotoxic cells, experiments were performed using Ciona intestinalis specimens stats collected from the same locale. We found that the viability of hemocytes, mixed in allogeneic combinations, did not decrease. In this respect Fuke and Numakunai (24) demonstrated that allogeneic contact reactions occurred by mixing hemocytes from Halocynthia roretzi of different locales, whereas no allogeneic reaction was ob- 
served between specimens of the same locale. Furthermore, a contact reaction can be revealed when heterospecific combinations involved two different Ciona species (14).

Perhaps not all hemocytes possess the cytotoxic capacity, since unidentified cell type(s) may be responsible for lytic activity. We observed that a relationship exists between hemocyte numbers and levels of cytotoxic activity; however, various levels of cytotoxic activity distinguish between different suspensions of pooled hemocytes prepared at 1.0-1.5 $\times 10^{7} / \mathrm{mL}$ (hemolytic degree from 64 to $92 \%$ ), or between different specimens showing the same hemocyte numbers. This individual variability could depend on cytotoxic hemocytes that can vary between several specimens.

Agglutinins were found in the reaction medium. In accordance with the release of lectins from hemocytes of Phallusia mamillata (25), they were quickly released from hemocytes and probably stimulated by the experimental conditions. Two agglutinins, anti-SE and antiRE, were distinguishable by their different $\mathrm{Ca}^{2+}$ dependence in agglutinating erythrocytes. These soluble factors, causing the formation of agglutinates in which hemocytes and erythrocytes come in contact, could be involved in a first step of the hemolytic reaction effected by hemocytes. As previously reported (26), naturally occurring lectins are present in the serum; the anti-SE and antiRE lectins appear to be similar to the agglutinins released from hemocytes. We do not have a clear understanding of the specificity of these molecules. According to Wright (27), they may be components of a defense system present in Ciona hemolymph.

The cytotoxic activity of Ciona hemocytes against erythrocytes cannot be considered as a component of the natural cellular immunity of this ascidian. However, the possibility exists that a similar cytotoxic system, linked to hemocyte membranes, is responsible for in vitro contact reactions $(14,15)$, nonfusion reactions (16), and allograft rejection (20), in which cellular contact could be the basis for various cytotoxic responses.

Acknowledgements-We thank Professor E. L. Cooper, Department of Anatomy and Cell Biology U.C.L.A., for revising the manuscript. This work was supported by M.U.R.S.T. (40\% and 60\% 1990) and C.N.R. (90 03234.04).

\section{References}

1. Parrinello, N.; Arizza, V. Cytotoxic activity of the invertebrate hemocytes with preliminary findings on the tunicate Ciona intestinalis. Boll. Zool. 59:183-189; 1992.

2. Trinchieri, G. Biology of natural killer cells. Adv. Immunol. 47:187-376; 1989.

3. Young, J. D-E.; Cohn, Z. A. Cellular and humoral mechanism of cytotoxicity: Structural and functional analogies. Adv. Immunol. 41: 269-332; 1987.

4. Janeway, C. A. Natural killer cells. A primitive immune system. Nature 341:108; 1989.

5. Boiledieu, D.; Valembois, P. Natural cytotoxic activity of sipunculid leukocytes on allogeneic and xenogeneic erythrocytes. Dev. Comp. Immunol. 1:207-216; 1977.

6. Valembois, P.; Roch, P.; Boiledieu, D. Natural and induced cytotoxicities in sipunculids and annelids. In: Manning, M. J., ed. Phylogeny of immunological memory. Amsterdam: Elsevier/ North Holland Biomedical Press; 1980:47-55.

7. Decker, J. M.; Elmholt, A.; Muchmore, A. V. Spontaneous cytotoxicity mediated by invertebrate mononuclear cells toward normal and malignant vertebrate targets: Inhibition by defined mono and disaccharides. Cell. Immunol. 59:161-170; 1981.

8. Yoshino, T. Y.; Tuan, T. L. Soluble mediators of cytotoxic activity in hemocytes of the Asian clam, Corbiula fluminea. Dev. Comp. Immunol. 9:515-522; 1985.

9. Luquet, G.; Leclerc, M. Spontaneous and induced cytotoxicity of axial organ cells from Asterias rubens (Asteroid-echinoderm). Immunol. Lett. 6:339-344; 1983.

10. Bertheussen, $K$. The cytotoxic reaction in allogeneic mixtures of echinoid phagocytes. Exp. Cell Res. 120:373-381, 1979. 
11. Tyson, C. J.; Jenkin, C. R. The cytotoxic effect of hemocytes from the crayfish (Parachaeraps bicarinatus) on tumor cells of vertebrates. Aust. J. Exp. Biol. Med. Sci. 52: 915-923; 1974.

12. Roder, J. C.; Karre, K.; Kiessling, R. Natural killer cells. Prog. Allergy 28:66-159; 1981.

13. Söderhäll, K.; Wringren, A.; Johansson, M. W.; Bertheussen, K. The cytotoxic reaction of hemocytes from freshwater crayfish Astacus astacus. Cell. Immunol. 94:326-332; 1985.

14. Fuke, M. T. "Contact reaction" between xenogeneic or allogeneic coelomic cells of solitary ascidians. Biol. Bull. 158:304-315; 1980.

15. Kelly, K.; Cooper, E. L.; Raftos, D. A. In vitro allogeneic cytotoxicity in the solitary urochordate Styela clava. J. Exp. Zool, 262:202208; 1992.

16. Saito, Y.; Watanabe, H. Colony specificity in the compound ascidian, Botryllus scalaris. Proc. Jpn. Acad. [B] 58:105-108; 1982.

17. Parrinello, $\mathbf{N}$. The reaction of Ciona intestinalis (Tunicata) to subcuticular erythrocyte and protein injection. Dev. Comp. Immunol. 5(Suppl. 1):105-110; 1981.

18. Parrinello, N.; Patricolo, E.; Canicatti', C. Inflammatory-like reactions in the tunic of Ciona intestinalis (Tunicata). I. Encapsulation and tissue injury. Biol. Bull. 167:229-273; 1984.

19. Parrinello, N.; De Leo, G.; Di Bella, M. A. Fine structural observations of the granulo- cytes involved in the tunic inflammatory-like reaction of Ciona intestinalis (Tunicata). J. Invert. Pathol. 56:181-189; 1990.

20. Raftos, D. A.; Tait, N. N.; Briscoe, D. A. Cellular basis of allograft rejection in the solitary urochordate Styela plycata. Dev. Comp. Immunol. 11:713-726; 1987.

21. Raftos, D. A.; Cooper, E. L. Proliferation of lymphocyte-like cells from the solitary tunicate, Styela clava, in response to allogeneic stimuli. J. Exp. Zool. 260:391-400; 1991.

22. Snedecor, G. W.; Cochran, W. G. Statistical methods, 7th ed. Ames, IA; The Iowa State University Press; 1980:488.

23. Kabat, E. A.; Mayer, M. M. Experimental immunochemistry. 2nd ed. Springfield, IL: C. L. Thomas; 1961.

24. Fuke, M. T.; Numakunai, T. Allogeneic cellular reactions between intra-specific types of a solitary ascidian, Halocynthia roretzi. Dev. Comp. Immunol. 6:253-261; 1982.

25. Arizza, V.; Parrinello, N.; Schimmenti, S. In vitro release of lectins from hemocytes of Phallusia mamillata. Dev. Comp. Immunol. 15:219-226; 1991.

26. Parrinello, N.; Patricolo, E. Erythrocyte agglutinins in the blood of certain ascidians. Experientia 31:1092-1093; 1975.

27. Wright, R. K.; Cooper, E. L. Immunological maturation in the tunicate Ciona intestinalis. Am. Zool. 15:21-27; 1975. 
